\title{
Prosper Mérimée, textes réunis et présentés par Antonia Fonyi
}

\section{Michel Arrous}

\section{Q OpenEdition \\ 1 Journals}

\section{Édition électronique}

URL : http://journals.openedition.org/studifrancesi/5674

DOI : 10.4000/studifrancesi.5674

ISSN : 2421-5856

Éditeur

Rosenberg \& Sellier

\section{Édition imprimée}

Date de publication : 1 septembre 2011

Pagination : 431-432

ISSN : 0039-2944

\section{Référence électronique}

Michel Arrous, «Prosper Mérimée, textes réunis et présentés par Antonia Fonyi », Studi Francesi [En ligne], 164 (LV | II) | 2011, mis en ligne le 30 novembre 2015, consulté le 08 janvier 2021. URL : http:// journals.openedition.org/studifrancesi/5674; DOI : https://doi.org/10.4000/studifrancesi.5674

Ce document a été généré automatiquement le 8 janvier 2021.

\section{(c) (i) (2)}

Studi Francesi è distribuita con Licenza Creative Commons Attribuzione - Non commerciale - Non opere derivate 4.0 Internazionale. 


\title{
Prosper Mérimée, textes réunis et présentés par Antonia Fonyi
}

\author{
Michel Arrous
}

\section{RÉFÉRENCE}

AA. VV., Prosper Mérimée, textes réunis et présentés par Antonia FoNYI, Caen, Lettres modernes Minard, «Écritures XIX», 6, 2010, 264 pp.

1 Un quart de siècle après Stendhal, Mérimée a eu enfin sa Décade! En septembre 2007, on a pu entendre à Cerisy vingt-trois communications dont trois ont été déjà publiées dans le premier des Cahiers Mérimée (2009). Dans sa présentation (pp. 3-10) Antonia FONYI retrace l'évolution des études mériméennes: pendant longtemps bien des aspects de l'œuvre furent à peu près ignorés et perdurèrent de vieux clichés sur un écrivain accusé, entre autres défauts, de froideur et de manque d'imagination, sans parler des griefs politiques: conservateur à tous crins et valet de Napoléon III. Le renouveau se manifeste aujourd'hui sous différentes formes: un séminaire à Paris III, une Société Mérimée, la publication des Cahiers, l'édition des CEuvres complètes en cours chez Champion et, enfin, la publication des actes du colloque de Cerisy qui contribuent à l'élaboration de la nouvelle image de l'homme et de l'œuvre que les colloques de 1997 et 2006 avaient esquissée. Quatre sections traitent des problématiques nouvelles: «Mérimée écrivain: distance versus violence», «Vivre et écrire l'histoire», «Art et archéologie», «Ailleurs mériméens».

2 Dans Mérimée et les fantômes à travers sa correspondance (pp. 13-22), Daniel S ANGSUE, spécialiste des vampires littéraires, rappelle que la grande famille des morts-vivants a délégué revenants en corps et fantômes dans l'œuvre de Mérimée. L'attitude de l'écrivain face au surnaturel et à l'occulte, dont les phénomènes défraient l'actualité dans les années 50, est ambiguë: le rationaliste qu'il est ou s'efforce d'être ne croit pas ou plutôt, comme il l'affirme en 1859, ne croit plus aux fantômes, ce qui n'empêche pas une certaine propension à l'irrationnel, ni la composition d'histoires de fantômes! On 
ne peut s'empêcher de penser à la boutade de Sainte-Beuve: «Mérimée ne croit pas que Dieu existe, mais il n'est pas bien sûr que le Diable n'existe pas». Il est évident que les forces obscures «informent en profondeur son imagination». On reste en compagnie des spectres avec Scott CARPENTER (Vampirisme et production littéraire. Se nourrir du sang des autres, pp. 23-32). Au centre de La Guzla, le chapitre «Sur le vampirisme» illustre le penchant de Mérimée pour la mystification et en même temps offre un bel exemple de production du texte par vampirisation de la littérature occulte à laquelle Mérimée goûta dans sa jeunesse (Dom Calmet, Nodier, Fortis, Lavallée, etc...). Le parallèle qui s'établit entre le vampire et le narrateur se retrouve dans d'autres œuvres sous la forme d'une feinte qui conduit à une "vérité enfouie, souvent sanglante, toujours monstrueuse». La violence étant une composante connue de l'œuvre de Mérimée, Thierry SANTURENNE a choisi les «scènes féodales» de La Jaquerie dans lesquelles il voit un théâtre du conflit. Il s'agit moins d'une simple reconstitution historique que d'une entreprise de démystification visant le présent, la Restauration, dans laquelle s'affirmerait une réalité transhistorique, une loi anthropologique se manifestant par «l'omniprésence de la violence dans les sociétés humaines» ("La Jaquerie" de Mérimée. Une dramaturgie de la violence sociale, pp.33-42). Cette violence se retrouve dans le clivage des rapports entre parents et enfants qui renverrait à l'opposition esthétique entre classicisme et romantisme: Christian Chelebourg (Le sens de la famille. Filiation, transmission, générations chez Prosper Mérimée, pp. 43-52) explore les liens du sang, les tensions familiales et la rupture entre générations dans le diptyque d'Inès Mendo, dans Les Espagnols en Danemark et, de façon plus détaillée, dans Colomba qui «signe un renoncement à l'hérédité de la haine». On quitte les territoires de la violence avec Sylvain LEDDA (Musset et Mérimée dramaturges de la fantaisie, pp. 53-65). En 1838, affligé par la médiocrité de la programmation théâtrale, Gautier souhaite qu'une pièce de Musset ou de Mérimée vienne renouveler la scène théâtrale française, à un moment où ni l'un ni l'autre ne se préoccupent plus de théâtre! On comprend son souhait, d'autant plus que Musset et Mérimée, dont la posture auctoriale et la stratégie sont identiques, ont donné avec leur théâtre dit de fantaisie, entre jeu et sérieux, une vision renouvelée de la réalité. Une comparaison attentive montre qu'on peut voir dans le Théâtre de Clara Gazul une des sources du théatre de Musset, particulièrement en ce qui concerne l'esthétique de la surprise, ainsi que les jeux de l'ironie et de la satire envers le romantisme de 1830. Anne GEISLER-SZMULEWICZ (Les nouvelles mondaines de Mérimée ou les comédies du cœur humain, pp. 67-77) constate que chez notre auteur «le cœur joue et se joue la comédie», dans un récit qui glisse vers la dérision farcesque, par exemple dans Le Vase étrusque et La Double Méprise où l'interprétation du dénouement peut paraître confuse, voire équivoque dans Arsène Guillot. Thierry OzWALD aborde le premier tome de la Correspondance générale, massif souvent évoqué et loué, mais peu étudié (“Correspondance" (1822-1835). Humoresques de Mérimée, pp. 79-92). Non sans arguments, il y voit "comme le laboratoire, le creuset ou l'atelier» des nouvelles. S'interrogeant sur la parole mériméenne, il relève que dans cet ensemble où l'humour et la volonté de transgression qu'il implique vont de pair avec l'humeur, aussi bien que dans les textes narratifs, la subversion ironique est partout. De l'humour à la désinvolture, il n'y a qu'un pas franchi par Philippe GARNIER qui se préoccupe de $L a$ «Sprezzatura» de Mérimée (pp.93-101). Une désinvolture non sans grâce parce qu'elle suppose le refus de l'emphase, du négligé et de la rudesse, et dans laquelle on reconnaît la leçon de Stendhal sur le style simple des classiques. C'est bien cette simplicité que Mérimée recherchera, dans un effort qui le rapproche en quelque sorte de l'idéal de Baldassar 
Castiglione recommandant de fuir l'affectation et prônant «une certaine désinvolture qui cache l'art».

3 La deuxième section est dédiée à Mérimée dans l'histoire et historien. Alain ScHMITT propose un inattendu Mérimée libéral (pp. 105-115), surtout quand on connait son conservatisme de plus en plus affirmé: un libéral à la manière de Guizot et des doctrinaires, déçu par la monarchie constitutionnelle à partir de 1839 et qui, après février 1848, s'écartera du clan pour devenir anti-démocrate, alors qu'il juge que les idées démocratiques «bien enracinées dans ce pays», autant qu'anti-légitimiste - les légitimistes n'étant que des «papistes». Jugeant vers la fin du Second Empire le gouvernement personnel aussi «impossible» que le gouvernement parlementaire, Mérimée sombrerait dans le fatalisme, se résignant à supporter l'alternance des saturnales démocratiques et du despotisme. C'est à l'historien que s'intéressent Pierre PONTHIER (Le Xénophon de Mérimée, pp. 117-128) et Michel GARCIA (La recherche historique chez Mérimée. Le cas de "Histoire de Don Pèdre I ${ }^{e r}$, Roi de Castille", pp. 129-136) qui prouvent que ce titre n'est pas usurpé. Fasciné par l'Anabase, - voir son article sur l'Histoire de la Grèce de George Grote - Mérimée donne à Xénophon une «dimension moderne, éclectique, plus proche des préoccupations de ses contemporains», alors que pour l'historien anglais il incarnait le seul génie athénien. D'autres désaccords sont soulignés dans le récit que Mérimée compose à partir de Xénophon et du texte de Grote. Et, remarque non moins intéressante, des similitudes sont relevées avec l'épisode final de Don Pèdre, par exemple avec le caractère dramatique du récit de Mérimée dont Grote avait d'ailleurs fait l'éloge. Michel GARCIA, qui a donné une nouvelle édition de l'Histoire de Don Pèdre Ir (Champion, 2009), étudie les sources de Mérimée dont l'optique a évolué à mesure que son projet avançait. Privilégiant la chronique d'Ayala dans l'édition de 1779, Mérimée s'est dispensé de recherches approfondies qu'il n'aurait sans doute pas pu mener à bien tant les sources étaient dispersées, ce qui ne l'empêcha pas de s'intéresser aux archives espagnoles dont il tira un très inégal profit, se défiant non sans raisons de certaines d'entre elles: «Le témoignage de la chronique [d'Ayala] reste donc prioritaire».

Dans la section réservée aux rapports de Mérimée avec l'art et l'archéologie, Bruno FOUCART propose, à partir des Salons de 1839 et 1853, un Mérimée en critique d'art (pp.141-155) et cherche à préciser la position esthétique de ce salonnier d'occasion doublé d'un technicien averti. On regrettera qu'à propos de sa réaction face à $L a$ Baigneuse de Courbet, l'analyse des complexes rapports qu'il entretint avec le réalisme soit en fait esquivée, notamment quand est évoquée l'opposition entre Fantaisistes - ce n'est pas une création de Mérimée! - et Réalistes. On pourrait en dire autant de son goût pour certains paysagistes français. Dans Prosper Mérimée et la Seconde République (pp. 157-168) Françoise BERCÉ rappelle qu'après février 1848 on put craindre le rôle de la commission des monuments historiques compromis, ce dont Mérimée s'inquiéta, plus vivement encore lors de l'insurrection de juin. La commission fut modifiée, mais ses principaux membres maintenus et Vitet réintégré sur intervention de Mérimée. Sous la Seconde République, de nombreux conflits opposèrent la commission aux préfets, maires, curés et conseils de fabrique, mais aussi au ministre de la Guerre. Le ralliement de l'inspecteur général au Second Empire s'expliquerait par son désir d'un gouvernement fort, seul capable à ses yeux d'assurer la politique de protection des monuments anciens initiée par la monarchie de Juillet. Mérimée, qui eut un rôle de premier plan dans le domaine de la protection et de la restauration des monuments, se 
préoccupa aussi des objets d'art en danger, même si le manque de crédits ne permit pas toujours leur restauration. Jannie MAYER, conservateur en chef du patrimoine, rappelle, à partir des Notes de voyage, les efforts de Mérimée pour élaborer une politique de protection des grands ensembles décoratifs (Mérimée et les objets d'art, pp. 169-178).

On trouvera dans les «Ailleurs mériméens» six études dont la proximité n'est pas évidente. C'est l'ethnographe et l'ethnolinguiste que privilégie Éric BORDAS dans Mérimée ou le romanesque de la linguistique (pp.181-191). Trois étapes: une période dominée par la convention du pittoresque pendant laquelle un imaginaire linguistique se fait jour, jusqu'au tournant de 1834 à partir duquel on assiste au développement d'un romanesque de la linguistique, enfin l'érudition linguistique "comme rêve des origines» l'emporte avec Carmen et Lokis. Patrick ReBollaR, à partir d'une base de données peu précise se livre à une exploration thématique intitulée Tourisme en Mérimée (pp. 193-203). Force est de constater que l'exploitation lexicométrique n'apporte rien qu'on ne sache déjà, si ce n'est quelques remarques pertinentes sur la place et le rôle du narrateur. On n'en dira heureusement pas autant des interventions de Michel CADOT sur Le monde slave de Mérimée (pp. 205-216) et de Jean CANAVAGGGIO sur Mérimée, lecteur de "Don Quichotte" (pp. 217-231) dont la précision érudite est indiscutable. M. Cadot évoque d'abord l'opinion largement négative que Mérimée avait des Polonais, puis ce petit compartiment du monde slave qu'était l'Illyrie auquel fut consacrée La Guzla, enfin il attire l'attention sur un ami de Pouchkine, S. A. Sobolevski, qui orienta l'esprit de Mérimée vers la Russie. Sobolevski connut Mérimée à Paris en 1829 et lui aurait donné ses premières leçons de russe, donc avant Mme de Lagrené. Est aussi souligné le rôle déterminant de Mérimée dans la découverte progressive de la littérature russe, particulièrement Pouchkine $(1849,1852,1868)$, Gogol auquel il consacra un grand article en 1851, suivi par la traduction du Revizor en 1852, et bien sûr Tourgueniev avec l'article sur les Récits d'un chasseur (1854) et les préfaces à Pères et enfants (1863) et à Fumée (1868). J. Canavaggio compare les deux préfaces que Mérimée écrivit pour Don Quichotte, en 1826 pour l'édition Sautelet, et en 1869 pour la traduction de Biard dont il pensait qu'elle allait supplanter celle de Viardot. Dans cette dernière préface, souvent sous-estimée, Mérimée, en désaccord avec l'interprétation romantique, s'appuie sur l'autorité de Valera qui avait récusé l'exégèse ésotérique de Benjumea. Autre hispaniste, autre chemin: François GÉAL, venu à Mérimée par l'entremise de l'adaptation de Carlos Saura, se penche sur la réinterprétation du mythe dont la notoriété date de l'opéra de Bizet, mythe que Saura se réapproprie en procédant à une hybridation de l'opéra avec le flamenco dans l'Espagne contemporaine, dans laquelle se lit une quête de l'identité nationale (Le mythe de Carmen entre les mains du cinéma espagnol. L'exemple de Carlos Saura (1983), pp. 233-244). Autres mythes, ceux de Don Juan et de Pygmalion que Marie-Noëlle Auguste retrouve associés dans "La Vénus d'Ille" de Mérimée ou la muette opératique (pp. 245-262). Un des hypotextes de Mérimée pourrait être l'opéra de F. Herold, Zampa ou la fiancée de marbre (1831), où figure le motif du mariage funeste avec une statue par le moyen d'un anneau. Il existe trois autres variations musicales: l'opéra de P.-H. Busser (1963), qui est aussi l'auteur du livret d'ailleurs fort proche de la nouvelle, avec quelques clins d'œil au Dernier des Valerii de James, L'Image de marbre du suisse Schoek (1919), qui a pris de grandes libertés avec les personnages de Mérimée, et enfin One Touch of Venus, comédie musicale de Kurt Weill (représentée à Broadway de 1943 à 1945, adaptée à l'écran en 1948, avec Ava Gardner, et 
souvent donnée en Angleterre), variation ironique du mythe de Pygmalion, qui n'est connue en France que depuis peu.

6 L'ensemble de ces quatre sections contribue, parfois inégalement, à l'enrichissement de l'image actuelle de Mérimée. 